\title{
Gender, Industries, And The Moral Reasoning Of Managers
}

\author{
Almerinda Forte, (Email: fortea@stjohns.edu), St. John’s University
}

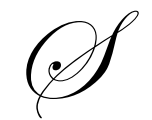

ome researchers believe that males and females develop moral reasoning in the same manner. Others state that males tend toward moral judgments based on the concept of "Justice" and women base their judgements on "Care." A third school believes that neither such cognitive elements as justice and care are as important as emotion, especially empathy, in moral action.

Kohlberg $(1958,1981)$ maintained that moral reasoning in males and females can be described by a single model of development. His advanced stages in moral reasoning are characterized by a set of abstract moral principles based on justice, equity, and equality. He addressed the gender controversy by attributing differences in the use of the care and justice orientations to the nature of the problem instead of the sex of the participant.

Johnston $(1979,1982,1988)$ reported that boys and girls were notably different in terms of their tendency to use a care or justice perspective in solving moral dilemmas. Johnston asked both boys and girls to select the "best" solution to the problem in several fables. Girls tended to select a care solution, whereas boys generally indicated a justice orientation in their moral reasoning. Gilligan $(1979,1982)$ suggested that gender differences exist in the ways that men and women approach and solve ethical problems.

Daniels, D'Andrea, and Hick (1995) conducted a study on Hawaiian youths. The purpose of the study was to investigate possible difference in the moral development of male and female youths. Participants in this study were 80 children and adolescents of Hawaiian ancestry. The method used to study moral development was the use of fables. Daniels, D'Andrea, and Hick concluded that gender differences in moral reasoning abilities did not exist between male and female Hawaiian participants in their study. They also found that the care perspective dominated the responses offered by both male and female students. What was also noted in the study was that the male participants predominantly responded from a care perspective in all but one of their spontaneous and best solutions.

Gilligan (1982) has argued that males and females in our society have different orientations to moral conflict. She holds that males typically take a justice orientation towards conflicts. Males emphasize the importance of rights, justice, and obligations in their process towards resolving conflicts. Females, according to Gilligan, have a care orientation which emphasizes the importance of human relations and the welfare and well being of all parties involved. Gilligan stresses that while males and females are capable of considering both perspectives, one perspective or orientation usually predominates.

Gilligan and Attanucci (1988) conducted a study entitled, Two Moral Orientations: Gender Differences and Similarities, which studied real-life dilemmas from 46 men and 34 women who were primarily adolescents and young adults. The study found that concerns about both justice and care are represented in people's thinking about real-life moral dilemmas. However, people tend to focus on one set of concerns and will minimally represent the other.

The study also found an association between moral orientation and gender with men and women using both orientations. Care-focus dilemmas are most likely to be presented by women and justice-focus dilemmas by men.

Skoe (1994) investigated Ethic of Care, Justice, Identity and Gender. The participants in Skoe's study, 76 female and 58 male volunteers, were recruited from several high school and university classrooms, including Harvard University, Boston, University, Northeastern University, University of Massachusetts, and high school students from the Boston area. The findings of the study indicated that both the care and justice aspects of moral development are related to identity for both men and women. Women had a stronger relationship between identity 
and care than that between identity and justice. The study also found no significant gender effect. Based on an analysis of the research, this study speculates that women manifest higher ethical orientation than men.

Giligan's 1982 charges of sex-bias in Kohlbergian moral judgment assessment has drawn attention to the gender variable. Rest's (1979) book, Development in Judging Moral Issues, reviewed 22 studies assessing sex differences, and found that only two studies had reported a significant difference in $\mathrm{P}$ score between males and females who used the DIT in their research (Chapter 5). Only about $6 \%$ of the variance is accounted for by the sex variable in those two studies. Thoma and Rest's (1986) book, Moral Development: Advances in Research and Theory, provides a more encompassing review and meta analysis in Chapter 4, which indicates that sex accounts for about one half of a percent of the variance in DIT scores. Their analysis shows that education accounts for about 250 times more variance. The analysis also shows that in DIT research sex differences are rarely significant in junior highs, senior highs, college and graduate students, or adults. Therefore it is not the case that at one age, one gender has an advantage while at another age the other sex has an advantage. Rest recommends in this chapter that whenever sex differences occur, it would probably be a wise idea to check for the influences of other variables, such as IQ, education, or socioeconomic status (SES).

Gender is not a powerful variable for Rest. He attributes the attention given to the sex variables in moral judgment research to current concern in society in general about sex discrimination. Rest believes the charge of sex bias in moral judgment assessment is based on not very cogent arguments and on ambiguous evidence. This issue is discussed in detail in Rest's 1979 book, Chapter 5, and in his 1986 book, Chapter 4.

The researcher addressed the weaknesses and strengths of both views, keeping in mind that any instrument is potentially biased to some extent. The DIT, however, appears to be the best instrument available to measure moral reasoning. This study hypothesized that there would be no significant relationship between gender and the moral reasoning of individual managers.

The researcher in this study was not able to find any studies or information on the moral reasoning of managers in various industries. However, numerous studies have been conducted on various professional fields such as accounting, nursing, teaching and medicine.

Armstrong $(1984,1987)$ explored accountants' ethical reasoning and moral development. The results of Armstrong's research showed that CPAs and accounting students tended to be at lower levels of ethical reasoning than comparable groups of college-educated adults or college-age students.

Lampe and Finn (1992) studied accounting and CPAs in public firms but excluded partners. They compared subjects' DIT results to responses on a questionnaire containing seven short ethical scenarios. The results of Lampe and Finn's research found that both accounting students and practitioners tend to have lower DIT P scores than college-aged students, college-educated adults, and other professional groups such as law and medicine.

Studying the development of moral reasoning in nurses are Crisham, 1981a; Felton \& Parsons, 1987; Gaul, 1987; Ketefian, 1981, 1989; Ketefian and Ormond, 1988; Mayberry, 1986. The moral reasoning of nurses was measured by the Defining Issues Test (DIT), or the Nursing Dilemma Test (NDT), developed by Crisham (1981b), which parallels the DIT. Crisham's research suggests that moral reasoning of nurses tends to increase with more formal education. The research showed that nurses' scores are usually equal to or sometimes higher than scores of other groups with similar academic credentials.

In the area of education, Diessner (1991) reviewed 30 studies and concluded that most teachers reasoned only at the conventional level. He used Kohlberg's interview format to measure the moral reasoning of teachers. Diessner found that most preservice and inservice teachers could recognize but were unable to produce postconventional thinking. The research also indicated that moral thinking is subject to change depending upon school leaders or the atmosphere of the schools in which the teachers serve. 
Husted (1978) studied the moral reasoning of 488 medical students by utilizing the DIT test. The research found that medical students showed a preference for reasoning at stages 5 and 6 .

Since the moral reasoning of individuals in various professions varies, this study found it appropriate to investigate the moral reasoning of individual managers in selective industries.

Kohlberg's theory of moral development provided the theoretical rationale for the research study, and James Rest's Defining Issues Test (DIT) was used to determine managers' moral development level. The ethical work climate theory of Victor and Cullen helped to determine the impact that corporate culture has on individual managers' moral reasoning in selected industries. Victor and Cullen concluded that the perceived ethical climate has an influence on the types of ethical conflicts considered and the process by which such conflicts are resolved (McKenna, 1993, p. 32).

Victor and Cullen's theory was used to determine the degree to which there was a relationship between selfreported corporate climate influences and the moral reasoning of top, middle and first-line management; and to what degree does the corporate climate relate to a manager's locus of control with respect to moral reasoning. Rotter's I-E scale was used to determine the relationship between a manager's locus of control to his/her moral reasoning. The selected demographic and institutional variables (age, work tenure, education, gender, management level and industry category) provided the useful information to investigate the moral reasoning of individual managers.

The study investigated three independent variables: reported perceived organizational ethical climate, locus of control and selected demographic and institutional variables. The moral reasoning of individual managers in these selected industries was measured by the short form of Rest's DIT, the dependent variable in this study.

The research method utilized in this study was a mail survey and analysis. A mail survey serves several purposes. First, a mail survey enables the study of a large sample, and in turn, increases the generalizability of the study. Second, as Dillman (1978) asserts, individuals tend to respond more honestly to surveys than to either telephone or personal interviews. Third, mail surveys can provide anonymity to survey respondents, which Babbie states, might increase the likelihood and honesty of responses (Babbie, 1990, p. 342). Fourth, the mail survey format tends to eliminate interviewer bias. Finally, survey research may be used to determine perceptions of persons (Borg and Gall, 1979, p. 27). Perceptions and opinions are vital to this study. Mail surveys do have disadvantages, however. They tend to have a low response rate, and they provide no assistance to respondents. They ask only standardized questions to all participants, and require valuable time to complete. By necessity, surveys must be of limited length. Despite the disadvantages of mail surveys, for this study, the advantages outweigh the disadvantages

A random sample of 400 managerial and executive level employees at a variety of organizations throughout the United States served as subjects for the study. This sample size was appropriate based on the number of independent variables being examined along with the dependent variable in this study (Cohen, 1988). Dun \& Bradstreet (D\&B), a well-respected provider of financial information and business services with a database of ten million different-sized companies, drew the random sample for this study. D\&B provided this researcher with a proportional stratified random sample of 400 managerial and executive level employees at a variety of organizations throughout the United States. The job titles included in this search were those at the managerial and executive levels. A proportional stratified random sample of Fortune 500 firms was supplied by D\&B to insure that the surveyed managers work for organizations that have defined top, middle, and first-line management levels. Excluded from this study were organizations with Standard Industrial Classification (SIC) codes that related to agriculture, forestry, fishing, mining, construction, and government. Organizations with such codes tend to have managerial structures which deviate from the traditional top, middle, and first-line structures.

The basic formula for calculating sample size in probability sampling assumes, at the extreme, an infinite population. A sample of 384 is sufficient to represent an infinite population (Cohen, 1988 and Wunsch, 1986). Based on the number of variables in this study and assuming that the researcher is drawing a sample from a very large population, a sample of 400 was an appropriate sample size for this study. The target alpha level of 
significance was set at .05 as this level is a tolerable significance criterion in social science and educational research (Kerlinger, 1973). The unit of analysis was the individual respondent.

Each participant in the survey received a packet containing the short form of James Rest's Defining Issues Test (DIT), Rotter's I-E Scale, a Demographic and Institutional Questionnaire, Victor and Cullen's Five Ethical Climate Types Defined, a response postcard, and a return self-addressed, stamped envelope. Dillman's Total Design Method (TDM) recommendations were followed. The study utilized the short form of James Rest's Defining Issues Test (Rest, 1986), the responses to which determine the reasoning and the level of an individual's moral development. Through a series of responses related to scenarios of ethical dilemmas, this instrument measures the moral reasoning development of an individual predicated on Kohlberg's stages theory (Rest, 1986). Victor and Cullen's ethical climate types questionnaire was used to identify managers' perceptions of their organizations' climate, and Rotter's I-E Scale was used to assess the locus of control of individual subjects. The demographic questions inquired about management level, age, education, work tenure, and gender. D\&B provided the respondent's institutional information, which was confirmed by each respondent ( see Figure1).

The TDM entailed utilizing an advance notice letter, followed by a mailing which included a cover letter, the research instrument, and anonymous response card, and then two follow-up mailings. A total of 400 questionnaires were mailed. Of the 224 received questionnaires, 10 were discarded because of errors or inconsistencies, resulting in 214 useable questionnaires, for a response rate of 58\% and a usable response rate of $55 \%$.

\section{HYPOTHESES TESTS}

\section{Hypothesis 1}

H1 There will be no significant relationship between gender and the moral reasoning of individual managers.

Table 37

Independent Sample Test t-test for Equality of Mean P Scores and Gender

$(\mathrm{N}=214)$

\begin{tabular}{|lcc|}
\hline Variables & t & p value \\
\hline "P" Scores and Gender & 1.363 & .174 \\
\hline
\end{tabular}

This hypothesis was tested by using a two tailed t-test. The means of two separate groups (male and female) were compared for statistically significant differences. The mean for this study's dependent variable (Pscore results presented in Table 37), did not indicate statistical significance, $t=1.363$ and $p$ value .174 . This study is in accordance with Kohlberg's model which maintains that moral reasoning in males and females can be described by a single model of development.

While the mean "P" scores for females were higher than the mean "P" scores for males, no statistically significant correlations were found between gender and "P" scores. This finding is consistent with research conducted by Rest (1979) (1988), Derry (1989) and Harris (1990) and Pennino (2001). Rest found minimal differences between the moral reasoning scores of men and women. However, when differences did exist, females scored higher. Rest found that differences due to gender were not powerful when correlated with "P" scores. (Harris also found no differences between genders). Harris states, that with the exception of the self-interest construct, females, as a group, are not different from males in their degree of tolerance/intolerance to fraud, coercion, influence dealing, and deceit (1990, p. 744). Derry also found no moral reasoning differences between males and females. Derry's theory is that if general difference exist between men and women, they do not carry over into strong organizational cultures where both women and men are trained to think and judge as corporate members (Derry, 1989, p. 859). Pennino (2001) also did not find any difference between the moral reasoning of men and women. 
Gilligan $(1979,1982)$ suggested that gender differences exist in the ways that men and women approach and solve ethical problems. She has argued that males typically take a justice orientation towards conflicts, emphasizing the importance of rights, justice, and obligations in the resolution of conflicts. Females, according to Gilligan, have a caring orientation, which emphasizes the importance of human relations and the welfare and well being of all parties involved. Gilligan also stresses that both males and females are capable of considering both perspectives, but one perspective or orientation predominates. Gilligan's position was not supported in this study. It should also be noted that there were only 39 women in this cell. Therefore, the statistical power of this test is relatively low. This finding is consistent with research conducted by Rest(1979) (1988), Derry (1989) Harris (1990) and Pennino (2001). The results support hypothesis 1.

\section{Hypothesis 2}

H2 There will be no significant relationship between industry types (SIC Codes) and the moral reasoning of individual managers.

Table 39

Analysis of Variance of P Scores Between Industry Types

$(\mathrm{N}=214)$

\begin{tabular}{|lcc|}
\hline Variables & F & p value \\
\hline "P" Scores and Industry Types & 1.553 & .188 \\
\hline
\end{tabular}

This hypothesis was tested by using analysis of variance (ANOVA). Industry types (SIC codes) versus Kohlberg's six stages of moral development (is measured by James Rest's DIT) was tested for significance. The mean for this study's dependent variable, P-score (results presented in Table 39), did not have a statistical significance, $F=1.553$ and $P$ value $=.188$. Armstrong (1984, 1987), Lampe and Finn (1992), Crisham (1981), Diessner's (1991), and Husted (1978) found that some of the service professions are prone to different levels of moral reasoning. The findings of this study might suggest that there is something inherent in the industry's process that causes individual thought mechanisms to develop or not to develop to higher modes of moral development. The results support hypothesis 2 .

\section{Hypothesis 3}

H3 There will be no significant relationship between manager's locus of control and selected demographics (age, work tenure, management levels, gender, education and industry types).

This hypothesis was tested by using Pearson Correlation Coefficient (r), analysis of variance (ANOVA) and two tailed t-test.

Table 44

Independent Sample t-test for Equality of Means: Locus of Control and Gender $(\mathrm{N}=214)$

\begin{tabular}{|lcc|}
\hline Variable & $\mathbf{t}$ & p value \\
\hline Locus of Control Gender & 1.336 & .723 \\
\hline $\begin{array}{l}\text { 3d. Locus of control versus gender was tested by a two tailed t-test. Locus of control and gender were not } \\
\text { significant in this study, } \mathrm{t}=1.336 \text { and } \mathrm{p} \text { value }=.723 \text {, as indicated in Table } 44 .\end{array}$
\end{tabular}

According to Rotter's theory, males are more internal (locus of control) than females. This study found that males were slightly more internal than females, but the results were not statistically significant. 
As indicated in the descriptive statistics, 175 male respondents exhibited lower mean I-E scores than 39 female respondents. The mean I-E scores were 6.7 and 7.6 respectively. Males were slightly more internal than females in this study. The findings of this study support hypothesis $3 \mathrm{~d}$.

\section{Table46}

Analysis of Variance of Locus of Control and Industry Types $(\mathrm{N}=214)$

\begin{tabular}{|lcc|}
\hline Variable & F & p value \\
\hline Locus of Control and Industry Type & .821 & .513 \\
\hline
\end{tabular}

3f. Locus of control versus industry types was tested by analysis of variance (ANOVA). Locus of control and industry types were not statistically significant in this study, $\mathrm{F}=.821$ and $\mathrm{p}$ value $=.513$. See Table 46.

Based on the descriptive statistics that some industries are prone to lower or higher I-E scores, one would speculate that there is something inherent in the industry's process that causes individual thought mechanisms to mature (have an internal locus of control) or not to evolve (external locus of control); however, this study did not find a significant relationship between locus of control and industry types.

As indicated in the descriptive statistics, respondents from the transportation, communication, and utilities industry exhibited the lowest mean I-E score of 6.2, and respondents from the finance, insurance, and real estate industry exhibited the highest mean I-E score of 7.5. The findings of this study support hypothesis $3 \mathrm{f}$.

\section{Hypothesis 4}

H4 There will be no significant relationship between selected demographics (age, work tenure, education, gender, management levels and industry types) and perceived organizational ethical climate types (Caring, Law and Code, Rule, Instrumental, and Independent).

This hypothesis was tested by using analysis of variance (ANOVA). The multiple means were compared

Table 51

Chi-Square Test and Cramer's V for Gender and Ethical Climate Types

$(\mathrm{N}=214)$

\begin{tabular}{|lcccc|}
\hline Variables & Chi-Square Value & df & p value & Cramer's V \\
\hline Gender and Ethical Climate & 2.897 & 4 & .575 & .116 \\
\hline
\end{tabular}

4d. Gender versus perceived ethical climate types was not statistically significant in this study; the Chi-Square value was 2.897 and $\mathrm{p}$ value .575 . See Table 51 .

This finding supports the theory of Rest (1979) (1988), Derry (1989), Harris (1990) and Pennino (2001) that no differences exist in the moral reasoning of males and females in a corporate setting.

As indicated in the descriptive statistics, the majority of both male and female respondents perceived their organizational ethical work climate type to be Rule. The findings of this study support hypothesis $4 \mathrm{~d}$. 
Table 54

Chi-Square Test and Cramer's V for Industry Types and Ethical Climate Types

$(\mathrm{N}=214)$

\begin{tabular}{|lcccc|}
\hline Variable & Chi-Square Value & df & p value & Cramer's V \\
\hline Industry Types and Ethical Climate Types & 19.289 & 16 & .254 & .150 \\
\hline
\end{tabular}

4f. Industry types versus perceived ethical climate types was not statistically significant in this study; the Chi-Square value was 19.289 and $\mathrm{p}$ value $=.254$. See Table 54 .

Certain industries may be prone to certain perceived ethical climate types due to the nature of the business or industry. However, this study did not find a significant relationship between industry and perceived ethical climate types. The findings of this study support hypothesis $4 \mathrm{f}$.

\section{Hypothesis 5}

H5 There will be no significant relationship between an individual's locus of control, selected demographics and perceived organizational ethical climate to the moral reasoning of individual managers.

Table 55

Analysis of Variance of Locus of Control, Selected Demographics and Ethical Climate Types to Moral Reasoning

$(\mathrm{N}=214)$

\begin{tabular}{|lccc|}
\hline Variables & R square & F & p value \\
\hline Locus of Control, Selected Demographics and Ethical Climate Types & .082 & 1.525 & .117 \\
\hline
\end{tabular}

This hypothesis was tested by first sorting the information by industry type and then by performing regression analysis on the data. The DIT test $\mathrm{P}$ score, which is the dependent variable, was a function of locus of control, age, work tenure, top management, middle management, lower management, education, gender, and the five perceived ethical climate types (Caring, Law and Code, Rule, Instrumental and Independence). Table 55 shows how the distribution varies as a function of all the variables, and the degree to which each variable impacts the result. As indicated in Table 55, the variables resulted in an $\mathrm{R}$ square of $.082, \mathrm{~F}=1.525$ and $\mathrm{p}$ value of .117 .

As can be seen from Table 56, the strongest contributing factor to the variance in $\mathrm{P}$ scores was industry types $($ Beta $=-1.827, \mathrm{p}<.05)$. The second strongest contributing factor was gender $($ Beta $=-5.735, \mathrm{p}<.05)$. The variables industry and gender explain $4.6 \%$ of the variations in the dependent variable $\mathrm{P}$ score.

A reported $\mathrm{R}$ square of .023 for industry types, $\mathrm{F}=4.995$ and $\mathrm{p}$ value .026 . A reported $\mathrm{R}$ square for industry types and gender of $.046, \mathrm{~F}=5.057$ and $\mathrm{p}$ value .007 . These independent variables found a weak statistical significance. See Table 56 
Table 56

Multiple Regression Analysis Results - Coefficients

$(\mathrm{N}=214)$

\begin{tabular}{|c|c|c|c|}
\hline & $\underline{\text { R square }}$ & F ratio & p value \\
\hline Industry Types & .023 & $\overline{4.995}$ & .026 \\
\hline Industry Type and Gender & .046 & 5.057 & .007 \\
\hline Variables & Beta & & p value \\
\hline$\overline{\mathrm{I}-\mathrm{E} \text { Scale }}$ & $-7.4 \overline{50 \mathrm{E}-02}$ & & .789 \\
\hline Gender & -5.735 & & $.044 *$ \\
\hline Age & -.146 & & .271 \\
\hline Education & .376 & & .736 \\
\hline Management Levels & 1.098 & & .468 \\
\hline Work Tenure & $-8.816 \mathrm{E}-03$ & & .612 \\
\hline Industry & -1.827 & & $.016 *$ \\
\hline Caring & 1.408 & & .928 \\
\hline Law and Code & -5.610 & & .706 \\
\hline Rules & -1.301 & & .931 \\
\hline Instrumental & -6.342 & & .694 \\
\hline Independent & -1.046 & & .946 \\
\hline
\end{tabular}

\section{CONCLUSIONS AND IMPLICATIONS}

The following section outlines the major conclusions and implications drawn from the findings of this study. This section will first outline the conclusions and implications drawn from the statistically significant relationships and then the relationships with no statistical significance.

\section{Finding One}

A statistically significant relationship was found between age and organizational ethical climate types (Caring, Law and Code, Rule, Instrumental, and Independence).

The majority of the respondents, 134 or $62.6 \%$, who perceived their organizational ethical work climate type as Rule, reported a mean age of 47 . The 16 respondents or $7.5 \%$ who perceived their organizational ethical climate type to be Caring and the 38 respondents or $17.8 \%$ who perceived their organizational ethical climate type to be Law and Code reported a mean age of 44 . The six respondents or $2.8 \%$ who perceived their organizational ethical climate type to be Instrumental reported a mean age of 52, while the 20 respondents or $9.3 \%$ who perceived their organizational ethical climate type to be Independent reported a mean age of 51.

McKenna's (1993) research investigated fraudulent financial reporting by certified and noncertified management accountants in organizations with perceived different ethical work climates. He used the ethical climate construct of Victor and Cullen for his theoretical framework. The results of McKenna's study found that the first most identified organization was Law and Code, or 57\% of returns out of a total of 185 responses. A Rule climate was the second most frequently identified organizational climate type, representing $19 \%$ or 35 out of a total of 185 returns. Eight percent, or 15 of 185 returns, reflected a Caring type of organizational climate, and $4 \%$, or 8 of 185 returns, reflected an Instrumental type of organizational climate. Slightly different from McKenna's study, this study found that the first most identified ethical organizational climate type was Rule, or $62.6 \%$ of returns, or 134 of 214 responses. Law and Code was the second most frequently identified organizational climate type, at $17.8 \%$ or 38 of 214 returns and an Independence type of organizational climate was reported on 9.3\% of returns or 20 of 214 
responses. A Caring type of organizational climate was reported on $7.5 \%$ of returns, or 16 of 214 returns, and $2.8 \%$ or 6 of 214 returns reflected an Instrumental type of ethical organizational climate.

The researcher in this study found a statistical significance between age and perceived organizational ethical climate type. Age versus ethical climate types had a statistical significance in this study, $\mathrm{F}=1.981$, and $\mathrm{p}$ value .002. Slightly different from McKenna's study, this study reports that the first most identified ethical organizational climate type was Rule, followed by Law and Code, Independence, Caring, and Instrumental. What the results show is that the younger mean ages 44 (Caring), 45 (Law and Code), and 47 (Rule) are associated with the more ethical organizational climate types. McKenna's study found that the first most identified organization was Law and Code, followed by Rule, Independence, Caring, and Instrumental respectively.

Since the older managers and executive level employees have more work experience than the younger employees, they may have suffered more disappointments in their work career which may have affected their perception of their organizational ethical work climate. Managers and executive level employees of any age, especially older managers, could possibly benefit from training interventions geared to refocus their thought processes in a more ethically attuned direction.

The implication of this finding, regarding business education, reinforces the concept that business ethics should continue to be strongly emphasized in business curricula. All business subjects, including accounting, management and marketing, should challenge students with ethical dilemmas and moral reasoning issues. This will help emphasize that ethical soundness is of vital importance in corporate America.

\section{Finding Two}

A statistically significant relationship was found between management levels and organizational ethical climate; the F ration was 4.773 and $\mathrm{p}$ value .009 . This study found that both the majority of the executive respondents, 85 , and the majority of first-line management respondents, 14 , perceived their organizational climate to be Rule. Thirty-five middle managers, not a majority, reported a perceived organizational ethical work climate type of Rule. Three first-line managers, six middle managers, and seven executive managers reported a perceived organizational ethical work climate type of Caring. Thirteen first-line managers, eight middle managers, and 17 executive managers reported a perceived organizational ethical work climate type of Law and Code. Two first-line managers and, two middle managers reported a perceived organizational ethical work climate type of Instrumental. One first-line manager, two middle managers, and 17 executive managers reported a perceived organizational ethical work climate type of Independent.

Lewin and Stephens (1994) state that post-conventional individuals are particularly likely to become leaders (Kohlberg et al., 1983), and, as leaders, have a special opportunity for organizational impact. Postconventional or principled individuals believe that principles outweigh specific rules and interests, and view principles as universal, generalizable, and compelling. Principled individuals are very much concerned with right and wrong and with the dignity of the individual. Therefore, principled CEOs, leaders at the highest levels, will establish a climate of ethicality throughout their organizations and develop policies and processes that embody principles of respect for the individual. They will attempt to prevent wrongs committed in the name of the organization and not merely crimes of the organization (Lewin and Stephens, 1994, p. 198).

What should be noted is that the majority of the respondents were part of top management. A large majority of the respondents perceive their organization to be part of one of the more ethical climate types. D'Aquila (1997), as did Lewin and Stephens (1994), believes that top management sets the tone of the organization. This suggests that most top managers believe that their companies are striving to operate in an ethical manner.

This study supports D'Aquila (1997) and Lewin and Stephen's (1994) position that top management establishes the ethical tone of an organization. But ethical awareness needs to be reinforced by engaging top management in social and ethical audits of the company and by scheduling periodic seminars, which serve to maintain ethical thought processes. 
Business educators should stress that successful corporate leaders establish a climate of ethicality in their organizations by developing policies and processes that embody principles of respect for all individuals. Students can experience this through role playing and other interactions and assignments.

\section{Finding Three}

A statistically significant relationship was found between the selected demographics (industry types and gender) and the moral reasoning ability of individual managers.

The regression analysis showed the strongest contributing factor to the variance in $\mathrm{P}$ scores was industry types $($ Beta $=-1.827, \mathrm{p}<.05)$. The second strongest contributing factor was gender $($ Beta $=-5.735, \mathrm{p}<.05)$. The variables industry and gender explains only $4.6 \%$ of the variations in the dependent variable $\mathrm{P}$ score.

A reported $\mathrm{R}$ square of .023 for industry types, $\mathrm{F}=4.995$ and $\mathrm{p}$ value .026 . A reported $\mathrm{R}$ square for industry types and gender of $.046, \mathrm{~F}=5.057$ and $\mathrm{p}$ value .007 . The independent variables found a weak statistical significance. The variables industry and gender explains only $4.6 \%$ of the variations in the dependent variable $\mathrm{P}$ score.

No statistically significant relationship was found between an individual's locus of control, age, work tenure, management levels, education and the five ethical climate types to the moral reasoning ability of individual managers.

The implication of this finding is that managers or executive level employees should keep in mind that gender and the industry experience of a new employee might have an impact on his/her moral reasoning. However, age, work tenure, management levels, education, and the five ethical climate types may have no impact on his/her moral reasoning.

\section{Finding Four}

Female respondents reported a higher mean "P" score than male respondents; however, this study did not find a statistically significant relationship between male and female "P" scores. This finding is consistent with research conducted by Rest (1979) (1988), Derry (1989), and Harris (1990). Rest found minimal differences between the moral reasoning scores of men and women.

However, when differences did exist, females scored higher. Derry also found no moral reasoning differences between males and females. Derry's theory states that a general difference exists between men and women, it does not carry over into strong organizational cultures where both women and men are trained to think and judge as corporate members (Derry, 1989, p. 859). Harris states that women differ only in the self-interest construct. Females, as a group, are not different from males in their degree of tolerance/intolerance to fraud, coercion influence dealing and deceit (1990, p. 744).

Gilligan (1982), on the other hand, believes that males typically take a justice orientation toward conflicts, emphasizing the importance of rights, justice, and obligations in the resolution of conflicts. Females, according to Gilligan, have a care orientation which emphasizes the importance of human relations and the welfare and well being of all parties involved. She also stresses that both males and females are capable of considering both perspectives; however, one perspective or orientation predominates. This study did not support Gilligan's position.

The implication is that there are two orientations to the approach of moral development. Neither orientation is superior to the other. What might be of importance is whether an ethical dilemma or decision would require an individual to have more of a justice or caring orientation in order to solve that particular problem more ethically. Managers may need to use a justice orientation, as there are so many stakeholders that are involved or impacted when such decisions are made. The priorities and concerns of the group as a whole often take precedence over individual priorities in corporate organizations. 


\section{Finding Five}

No statistically significant relationship was found between manager's locus of control and selected demographics (age, work tenure, management levels, gender, education and industry types). Overall, respondents reported a mean I-E score of 6.9. The overall mean age reported by the respondents was 46.9. What should be noted is that this group of respondents was highly internal and an older group.

One hundred forty three respondents, a total of the largest group, had worked for their present firm for 6 months to 10 years. Twelve respondents had worked for their present firm for 6 months and had a mean I-E score of 6.1. Sixteen respondents had worked for their present firm for 1 year with a mean I-E score of 7.8. Thirty-two respondents had worked for their present firm for 2 years with a mean I-E score of 5.6. Twenty-six respondents had worked for their present firm for 3 years with a mean I-E score of 7.3, while twenty-seven respondents had worked for their present firm for 4 years with a mean I-E score of 6 . Nineteen respondents had worked for their present firm for 5 years with a mean I-E score of 7.8, and 11 respondents had worked for their present firm for 10 years with a mean I-E score of 7.

Eighty-nine respondents had a bachelor's degree and had a mean I-E score of 6.9. Fifty-seven respondents had a master's degree plus, with a mean I-E score of 6.7. Fifty respondents had a master's degree and had a mean IE score of 7.2, and fifteen respondents had some college and had a mean I-E score of 6.6. Only three respondents were high school graduates and had a mean I-E score of 3.3, representing the lowest mean I-E score. Overall, respondents reported a high level of education and a relatively high degree of internality.

One hundred seventy-five male respondents exhibited lower (more internal) mean I-E scores than the 39 females respondents. The mean I-E scores were 6.7 and 7.6 respectively. One hundred twenty-eight upper or executive level managers exhibited the lowest mean I-E scores of 6.6. Middle management reported mean I-E scores of 7.3 and first-line management reported mean I-E scores of 7.1. Overall, respondents reported a relatively high degree of internality. Not surprisingly, executive level employees exhibited the highest degree of internality. Individuals with a high desire for increased job satisfaction and high self-esteem tend to be motivated to improve their quality of life. These are the very individuals corporate America wants to place in top management positions.

Thirty respondents from the transportation, communication and utilities industry exhibited the lowest mean I-E scores of 6.2. Fifty-four respondents from the finance, insurance and real estate industry exhibited the highest mean I-E score of 7.5. The 51 respondents of the manufacturing industry reported a mean I-E score of 6.8 . The 35 wholesale and retail industry respondents reported a mean I-E score of 6.3, and the 39 respondents working in a service industry reported a mean I-E score of 7.1.

The implication of this finding from the perspective of a manager or executive level employee is that locus of control and selected demographics may not have any impact on how ethical a newly hired employee will be.

\section{Finding Six}

No statistically significant relationships were found between selected demographics (gender, and industry types) and organizational ethical climate types (Caring, Law and Code, Rule, Instrumental, and Independent).

Gender versus ethical climate types was not statistically significant in this study. This finding supports Rest (1979)(1988), Derry (1989), and Harris' (1990) theory that no differences between males and females moral reasoning ability appears in a corporate setting.

As indicated in the descriptive statistics the majority of both male and female respondents perceived their organizational ethical work climate type to be Rule. 
Industry types versus ethical climate types was not statistically significant in this study. As indicated in the descriptive statistics it seems that some industries might be prone to lower or higher levels of ethical climate types; however, statistical significance was not found in this study.

The implication of this finding, from a managerial or executive level employee's stand-point, is that gender and the industry experience of a new manager may have no impact on the potential success of the new manager's ability to help set the organizational ethical tone of that desired corporation.

A number of significant correlations were found that have the potential to impact individual managers and their organizations. A statistically significant relationship was found between age and organizational ethical climate types (Caring, Law and Code, Rule, Instrumental, and Independence). Another major finding from this study indicates a statistically significant relationship between management levels and organizational ethical climate. A statistically significant relationship was also found between the manufacturing industry's " $\mathrm{P}$ " score and the service industry's "P" scores. A statistically significant relationship was found between tenure and ethical climate types. Another finding from this study indicated a statistically significant relationship between education and ethical climate types. Also a statistically significant relationship was found between the selected demographics (industry types and gender) and the moral reasoning ability of individual managers.

\section{RECOMMENDATIONS}

The following recommendations are divided into two sections: recommendations for the field and recommendations for future research.

\section{Recommendations For The Field}

1. Managers or executive level employees might want to keep in mind that gender and the industry experience of a new employee might have an impact on his/her moral reasoning.

2. The result of this study might indicate that differences between males and females are not apparent in strong organizational cultures because men and women are trained to think and judge as corporate members. If this is true managers need to examine whether an ethical dilemma or decision would require an individual to have more of a justice or caring orientation in order to solve the particular problem in that situation more ethically. Managers may need to use a justice orientation, as there are so many stakeholders that are involved or impacted when such decisions are made.

\section{Recommendations For Future Research}

1. Future research should investigate the relationship between industry types, gender and moral reasoning. Managers who move from organization to organization travel with their professional baggage from previous positions, which may influence their moral reasoning. It would be beneficial to understand as much as possible the subtle variations that could affect a manager's moral reasoning.

2. Given the results of the various studies that have been conducted on the topic of gender and its relationship to moral reasoning, and given the varied results of these studies, further research is required. Further research could attempt to determine why differences found between managerial and executive women and males exist or do not exist. It could address specific factors by approaching the issue from a qualitative approach rather than the quantitative one used here. Interviews may offer more depth to the findings of this research and enhance its findings.

3. Further studies should be undertaken to ascertain whether corporate culture, the nature of the management position or other variables cause men and women to demonstrate similar or difference decision making processes when dealing with ethical dilemmas and moral reasoning in the work place. This study did not support Gilligan's theory; however a larger sample should be derived in future studies, in order to increase the statistical power of the analysis concerning gender.

4. Further research should be conducted on how locus of control impacts the various factors of age, work tenure, management levels, gender, education and industry types. 
5. Future research should investigate the relationship between gender and industry types and organizational ethical climate types. It would be beneficial to understand as much as possible how these variables affect variations in ethical climate types.

6. An analysis may be conducted of other professional organizations and groups, such as accountants, lawyers, doctors, and educators.

7. It would also be revealing to follow the individual business managers from selected industries on a longitudinal basis to determine the changes in their levels and positions over time and how time impacts their moral reasoning ability. Periodic examination over a number of years could reveal insight into how these changes affect the moral reasoning ability of selected business managers.

8. Additional research across industry types should be conducted to assess what if any differences occur in moral reasoning among those industries.

\section{CONCLUDING COMMENTS}

The value of ethical reasoning is that it is a premise upon which our country and our business enterprises are founded. High moral reasoning and the continued development of ethical standards are goals to which our government, businesses, and educational system must ascribe to.

Corporate America today must have higher ethics than ever before to ensure ethical soundness. They must accept responsibilities with respect to the environment; and that product safety and healthier working conditions must continue to improve as they have immensely improved in comparison to years past; and that racial and gender discrimination must continue to decrease. This is why it would be beneficial to understand as much as possible how ethical considerations impact on an organization's strategies and actions.

\section{REFERENCES}

1. Armstrong, M. (1984). Internalization of the Professional Ethic by Certified Public Accountants: A Multidimensional Scaling Approach. Unpublished: University of Southern California, Doctoral Dissertation.

2. Armstrong, M. (1987). Moral development and accounting education. Journal of Accounting Education, 27-43.

3. $\quad$ Babbie, E. (1990). Survey research methods (2nd ed.) Belmont, CA: Wadsworth, Inc.

4. Bigel, K. (1998). The Ethical Orientation of Financial Planners Engaged In Investment Activities: A comparison of Practitioners Based on Professionalization and Compensation Sources. Unpublished doctoral dissertation, New York University.

5. $\quad$ Borg, W.R. and Gall, M.D. (1979). Educational Research: An Introduction ( $3^{\text {rd }}$ ed.). Longman.

6. Borg, W.R. and Gall, M.D. (1989). Educational Research: An Introduction New York, NY: Longman.

7. Cohen, D.V. (1995). Moral climate in business firms: A framework for empirical research, Academy of Management 1995 Best Paper Proceedings.

8. Cohen, L.D. (1991). Sex differences in the course of personality development: a meta-analysis. Psychological Bulletin, 109, (2). 252-266.

9. Cohen, J. (1988). Statistical Power Analysis for the Behavioral Sciences. Hillsdale, NJ: Lawrence Erlbaum Associates, Publishers.

10. Crisham, P. (1981a). Moral Judgment of Nurses in Hypothetical and Nursing Dilemmas. Unpublished doctoral dissertation, University of Minnesota..

11. Crisham, P. (1981b). Measuring moral judgment in Nursing dilemmas. Nursing Research. 30 (2), 104110 .

12. D’Aquila, J. (1997). Internal Control Environment Forces and Financial Reporting Decisions Made by Financial Accountants. Unpublished doctoral dissertation, New York University.

13. Daniels, J., D'Andrea, M., \& Heck, R. (1995). Moral development and Hawaiian youths: Does gender make a difference? Journal of Counseling \& Development 74, 90-93.

14. Derry, R. (1989). An empirical study of moral reasoning among managers. Journal of Business Ethics, 8, pp. $855-862$. 
15. Derry, R. and R.M. Green. (1989) Ethical Theory in Business Ethics: A Critical Assessment. Journal of Business Ethics, 8,521-533.

16. Desjardins, C. (1996). Gender based teambuilding: Strengths men and women bring to effective leadership teams. National Institute for Leadership Development, Phoenix College, Phoenix, Az. Paper presented at the Fifth Annual Internal Conference for Community \& Technical College Chairs, Deans and Other Organizational Leaders, February 14-17, Phoenix/Mesa, Arizona.

17. Dickey, B., Kroll, B.S. \& Jenkins, L. (1987). Gilligan revisited: Methodological issues in the study of gender and moral development. Harvard Medical School, Department of Psychiatry, Communication, Colleges of St. Catherine and St. Thomas \& Massachusetts Mental Health Center. Presented at the National Convention of the Speech Communication Association, November, Boston, Massachusetts.

18. Diessner, R. (1991). Teacher education for democratic classrooms: Moral reasoning and ideology critique. 16th Annual Conference of the Association for Moral Education, Athens, GA.

19. Dillman, D.A. (1978). Mail and telephone survey: The total design method. New York, NY: John Wiley and Sons.

20. Dillman, D.A. (1999). Mail and electronic surveys, the tailored design method. New York, NY: John Wiley \& Sons, Inc.

21. Felton, G.M., \& Parsons, M.A. (1987). The impact of nursing education on ethical/moral decision making. Journal of Nursing Education, 26, 7-11.

22. Gaul, A.L. (1987). The effect of a course in Nursing ethics on the relationship between ethical choice and ethical action in baccalaureate Nursing students. Journal of Nursing Education, 26, 113-117.

23. Gilligan, C. (1982). In a different voice: Psychological theory and women's development. Cambridge MA: Harvard University Press.

24. Gilligan, C., \& Attanucci, J. (1988). Two moral orientations: gender differences and similarities. MerrillPalmer Quarterly, 34(3), 223-237.

25. Gilligan, C. (1979). Women's place in man's life cycle. Harvard Educational Review, 29, 119-133.

26. Gilligan, C. (1977). In a different voice: Women's conceptions of the self and of morality. Cambridge, MA: Harvard Educational Review 47: Harvard University.

27. Harris, J.R. (1990). Ethical values of individuals at different levels in the organizational hierarchy of a single firm. Journal of Business Ethics, 9, 741-750.

28. Husted, S.D. (1978). Assessment of moral reasoning in pediatric faculty, house officers and medical students. Proceedings of the 17th Annual Conference on Research in Medical Education, 17, 439-441.

29. Johnston, D.K. (1979). Adolescents' responses to moral dilemmas in fables. Unpublished manuscript, Harvard Graduate School of Education.

30. Johnston, D.K. (1982). Responding to moral dilemmas in fables, ages six to eleven: A brief study of gender differences. Unpublished manuscript, Harvard Graduate School of Education.

31. Johnston, D.K. (1988). Adolescents' solutions to dilemmas in fables: Two moral orientations - two problem-solving strategies. In C. Gilligan, J.V. Ward, \& J.M. Taylor (Eds), Mapping the moral domain (pp. 49-72):. Cambridge, MA: Harvard University Press.

32. Jung, C.G. (1923). Psychological types. New York, N.Y. Harcourt, and Brace.

33. Kerlinger, F.H. (1986) Foundations of behavioral research (3rd edition). Holt, Rinehart, and Winston.

34. Ketefian, S. (1981). Moral reasoning and moral behavior among selected groups of practicing nurses. Nursing Research. 30, 171-176.

35. Ketefian, S. (1989). Moral reasoning and ethical practice. In J. Fitzpatrick, R. L. Taunton, and J. Benoliel (Eds.), Annual review of nursing research (pp. 173-195). New York: Springer.

36. Ketefian, S., and Ormond, I. (1988). Moral reasoning and ethical practice in nursing: An integrative review. New York: National League for Nursing.

37. Kohlberg, L. (1981) The Psychology of Moral Development Volume One Harper and Row

38. Kohlberg, L. (1970). Moral Stages and Moralization. Moral development and behavior New York, N.Y.: Holt, Rinehart \& Winston.

39. Kohlberg, L. (1984). The Psychology of Moral Development Volume Two. San Francisco: Harper \& Row Publishers. 
40. Kohlberg, L. (1969). Stage and sequence: the cognitive-developmental approach to socialization. Handbook of Socialization Theory and Research. Goslin D. (ed), Chicago, Rand McNally, pp. 347-480.

41. Kohlberg, L. (1969). Stage and sequence. , Handbook of Socialization Theory and Research Chicago, IL: Rand McNally.

42. Kohlberg, L. (1976). Moral stages and moralization; the cognitive developmental approach. Moral Development and Behavior. Lickona, T. (ed). New York: Holt, Rinehart, \& Winston, pp. 31-55.

43. Kohlberg, L. (1984). The Relationship of Moral Judgment To Moral Action, Morality, Moral Behavior and Moral Development. New York: John Wiley \& Sons.

44. Kohlberg, L. (1982). Essays On Moral Development: The Philosophy of Moral Development. San Francisco, CA: Harper \& Row.

45. Kohlberg, L. (1958). The Development of Modes of Moral Thinking and Choice in the Years 10 to 16. Unpublished Doctoral Dissertation, The University of Chicago.

46. Kohlberg L. Levine, C., and Hewer, A. (1983) Moral stages: a current formulation and a response to critics. Basel: Karger

47. Lampe, J., \& Finn, D. (1992). A model of auditors' ethical decision process. A Journal of Practice and Theory, Supplement, 1-21.

48. Lewin, A.Y., \& Stephens, C.U. (1994). CEO attitudes as determinants of organization design: An integrated model. Organization Studies, 15 (2), 183-212..

49. Litwin, G.H. and Stringer, R.A. (1968). Motivation and Organizational Climate, Harvard Business School

50. Mayberry, M.A. (1986). Ethical decision making: A response of hospital nurses. Nursing Administration Quarterly, 10 (3), 75-81.

51. McKenna, J.N. (1993). Ethical Dilemmas In Financial Reporting Situations and The Preferred Mode of Resolution of Ethical Conflicts As Taken By Certified and Noncertified Management Accountants In Organizations With Perceived Different Ethical Work Climates. Unpublished doctoral dissertation, New York University.

52. Pennino, C. (2001). The Relationship Between Managerial Decision Style, Principled Ethical Reasoning, and Selected Variables in Business Organizations. Unpublished doctoral dissertation, New York University.

53. Rest, J.R. (1983). Morality. Handbook of Child Psychology, edited by P. Mussen, $4^{\text {th }}$ Edition, Vol 3 on Cognitive Development, pp. 556-629. New York, NY: John Wiley \& Sons.

54. Rest, J.R. (1983). Morality. Handbook of Child Psychology, edited by P. Mussen, $4^{\text {th }}$ Edition, Vol. 3 on Cognitive Development, pp. 556-629. New York, NY: John Wiley \& Sons.

55. Rest, J.R. (1979). Development in Judging Moral Issues Minneapolis, Minnesota, University of Minnesota Press.

56. Rest, J.R. (1982, February). A psychologist looks at the teaching of ethics. Hastings Center Report pp. 2936.

57. Rest, J.R. (1986a). DIT Manual (Third Edition, 8/90 Revision). Minneapolis, MN: Center for the Study of Ethical Development.

58. Rest, J.R. (1988). Why Does College Promote Development in Moral Judgment? Journal of Moral Education, 17 (3), 183- 193.

59. Rest, J.R. and Narvaez, D. (1994). Moral development in the professions: Psychology and applied ethics. Hillsdale, N.J. Lawrence Erlbaum Association, Publishers.

60. Rest, J.R. (1986) Moral development: Advances in research and theory. New York, NY: Praeger Publishers. Katholieke Universiteit Levven, Belgium Doctoral Dissertation.

61. Rotter, J.B. (1966). Generalized expectancies for internal versus external control of reinforcement. Psychological Monographics, 80 (1) 1-28

62. Rotter, J.B. (1982). The development and application of social learning theory: Selected papers New York: Praeger.

63. Skoe, E.E., \& Gooden, A. (1993). Care-based moral reasoning in male and female children. University of Tromso, Department of Psychology \& Acadia University. Paper presented at the 60th Anniversary Meeting of the Society for Research in Child Development, New Orleans, Louisiana, March.

64. Skoe, E.E., \& Diessner, R. (1994). Ethic of care, justice, identity, and gender: An extension and replication. Merrill-Palmer Quarterly 40 (2), 272-289. 
65. Tagiuri, R. and Litwin, G.H. (1968) Organizational Climate, Exploration of a Concept. Harvard University Law School.

66. Victor, B. and Cullen, J.B. (1987). A theory and measure of ethical climate in organizations. Research In Corporate Social Performance and Policy 9, 51-71.

67. Victor B. \& Cullen, J.B. (1988). The organizational basis of ethical work climates. Administrative Science Quarterly March, pp. 101-125.

68. Wunsch, D.R. (1986 February). Survey Research: Determining Sample Size and Representative Response. Restion, VA: Business Education Forum.

\section{NOTES}

